\title{
CLAVES PARA PENSAR LA FORMACIÓN DEL HÁBITO LECTOR
}

\section{Silvana Salazar Ayllón}

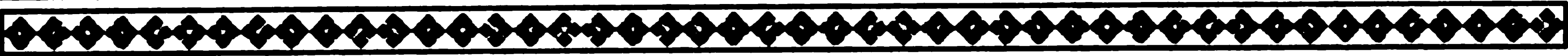

\section{El CLIMA SOCIAL DE LECTURA ${ }^{1}$}

El PeRÚ VIVE UN CLIMA social de lectura sin precedentes. A simple vista, esta afirmación parece exagerada, pero existen suficientes evidencias de que la población está reaccionando positivamente al conjunto de estímulos y esfuerzos - no siempre estructurados, pero válidos- para motivarlos hacia el ejercicio de esta importante activi-

${ }^{1}$ El concepto de clima social se refiere al «conjunto de características objetivas de la organización, perdurables y fácilmente medibles, que distinguen una entidad laboral de otra. Son unos estilos de dirección, unas normas y medio ambiente fisiológico, unas finalidades y unos procesos de contraprestación. Aunque en su medida se hace intervenir la percepción individual, lo fundamental son unos índices de dichas características». (Forehand y Gilmer, 1965). O esta otra definición: "Conjunto de percepciones globales (constructo personal y psicológico) que el individuo tiene de la organización, reflejo de la interacción entre ambos; lo importante es cómo percibe un sujeto su entorno, sin tener en cuenta cómo lo perciben otros; por tanto, es más una dimensión del individuo que de la organización». (Nicolás Seisdedos). 


\section{SILVANA SALAZAR AYLLÓN}

dad, cuya trascendencia para el desarrollo personal y social no se discute.

Estamos ante la existencia de condiciones que han generado un estado de ánimo, una predisposición y ciertas actitudes ${ }^{2}$ en las personas, de creciente acercamiento a los objetos de la lectura (libros), de sentimientos favorables hacia ellos (adquisición) y deseo de apropiarse de la actividad (ánimo lector, participación en eventos asociados a la lectura).

En este proceso han confluido diversas iniciativas. En principio, el estado, con sus acciones para enfrentar la emergencia educativa desde el año 2003; la dotación a los colegios públicos con más de 30 millones de libros ${ }^{3} y$, paralelamente, la generación de un marco normativo ${ }^{4}$ que incentiva el desarrollo de la industria editorial y la promoción de la lectura.

El hecho que más de 18 mil peruanos hayan sido preguntados por sus necesidades y prácticas lectoras, para la primera Encuesta Nacional sobre «Hábitos de lectura y ciudadanía informada en la población peruana-2004» $»^{5}$ junto con la campaña pública de «Un nuevo sol» para la culminación del nuevo edificio de la Biblioteca Nacional, contribuyeron a este clima.

De otro lado, la tenacidad de Promolibro -instancia multisectorial creada por la Ley del Libro para conducir la política de lectura en el Perú - ha permitido instalar en las zonas urbano-marginales más alêjadas de la capital nacional, más de un centenar de bibliotecas, e iniciar la elaboración consensuada del Plan Nacional de Lectura a través de mesas de concertación. Se ha instalado ya la primera ${ }^{6}$ en Lima, con la participación de representantes del estado, la industria gráfica y la sociedad civil organizada.

2 Regularidad en los sentimientos, pensamientos y predisposiciones del individuo para actuar en relación con algún aspecto de su ambiente (Secor y Backman, 1964).

${ }^{3}$ Fuente: Ministerio de Educación, portal web.

${ }^{4}$ Ley de Democratización del Libro y Fomento de la Lectura, $N^{\circ} 28086$, del 11 de octubre de 2003.

${ }^{5}$ Realizada por la Biblioteca Nacional, en convenio con la Universidad Nacional de Ingeniería. La muestra alcanza a 19,968 personas.

${ }^{6}$ En acto realizado el 13 de octubre de 2005. A éste lo antecedió la firma de la Declaración de Principios para el Plan Nacional del Libro y la Lectura, 


\section{LA FORMACIÓN DEL HÁBITO LECTOR}

En el ámbito del sector privado, el tema de la lectura ha ingresado en las agendas de las principales empresas, medios de comunicación, instituciones académicas y organizaciones sociales, sumándose a los esfuerzos del sector editorial por dinamizar y diversificar la producción y comercialización de libros, y sensibilizar a la población para generar disposiciones favorables hacia el libro y la lectura.

Esto explica la amplia oferta de actividades relacionadas con el fomento de la lectura: proyectos y experiencias de capacitación en lectura, creación de bibliotecas, realización de ferias locales, regionales y nacionales de libros, seminarios, conferencias, cuentacuentos, eventos motivadores y propaganda; que visibilizan a los actores y consumidores de la creación intelectual y productos para leer.

Las autoridades regionales y municipales ${ }^{7}$ no se han quedado al margen; algunos han optado por institucionalizar la hora pública de lectura en su ámbito; otros, por desarrollar programas de dotación de libros a bajo costo o gratuitos para los pobres, campañas de donación de libros, entre otras iniciativas.

En el plano simbólico, la creatividad se ha desbordado en innumerables carteles, afiches, eslóganes, consignas, y objetos artísticos y decorativos en forma de libros o que representan el acto de leer. Algunos ejemplos notables son los afiches de la librería Crisol en el año 2004, a propósito del campeonato de fútbol por la Copa América, que presentaba la caricatura de una selección de escritores iberoamericanos - uno representativo por cada país - vestidos de futbolistas; o los objetos de artesanía popular de Ayacucho, Chulucanas, Cusco y Loreto, que simbolizan la lectura y al libro. Otra muestra destacable es el libro de tela con la técnica de la arpillería, que recoge algunos cuentos andinos. El ambiente festivo ha estado matizado con caravanas, pasacalles, $y$ todo tipo de ceremonias, con igual propósito.

A partir de estos rasgos y de otros - que por razones de espacio no se consignan-, se puede establecer la configuración de un

suscrito por tres ministros; de Educación, de la Producción y de Justicia, así como por el director del INC y representantes de la sociedad civil. Cf. Web del Minedu, correspondiente al 13 de octubre de 2005.

7 Como las de Tumbes y Moquegua. En Lima, las municipalidades de Lima, San Borja, Miraflores e Independencia desarrollan programas estructurados y sostenidos de fomento de la lectura. 


\section{SILVANA SALAZAR AYLLÓN}

clima social favorable a la lectura, con base en tres elementos: 1) la intensificación y extensión del discurso sobre la importancia del libro y la lectura; el que no es sólo cognitivo, sino que está imbuido de tonalidades afectivas o modos de sentir tanto de los productores, como de los receptores del discurso; 2) la circulación intensiva y extensiva de libros, que es el soporte material del proceso de lectura; y 3) la consecuencia práctica de la combinatoria de los elementos anteriores, expresada en el mejoramiento de las disposiciones, actitudes y comportamientos personales asociados a la actividad lectora -aunque ello no necesariamente implique una correlación directa con su ejercicio-.

En efecto, la adquisición de libros, la concurrencia a las ferias y eventos culturales, el interés por conocer a los escritores, la disposición a colaborar con las campañas por la lectura y, en general, el aumento de los consumos de objetos culturales asociados, indican que las personas están elaborando sentidos válidos para sí en relación con la actividad lectora .

Un ejemplo de ello es el éxito de la X Feria Internacional del Libro de Lima - realizada en julio de 2005-, tanto en ventas (US \$ 1,5 millones) como en asistencia del público (240 mil visitantes), lo que constituye un incremento del $50 \%$ en relación con eventos similares realizados anteriormente.

No obstante, si bien todos estos esfuerzos y avances son muy importantes $y$, en nuestra opinión, abonan a la afirmación de que existe un clima de lectura en el Perú, las personas no necesariamente están leyendo más, ni puede afirmarse que han internalizado esta actividad y que, por ello, están en camino a la formación de hábitos perdurables.

De hecho, los primeros sondeos, realizados por las propias editoriales y Promolibro, indican que las personas están comprando más libros, pero no necesariamente están leyendo más. Igualmente, no es significativo el incremento de lectores en los reportes de las bibliotecas públicas y escolares. Es decir, existen condiciones contextuales para avivar el fuego de la lectura, pero el carbón todavía no está encendido como para arder por sí mismo. Esto no desvaloriza la atmósfera social de lectura que se ha generado; por el contrario, significa que estamos frente a un valioso activo para la construcción de la sociedad lectora. 
La experiencia de Finlandia - país que, según la prueba PISA, cuenta con mayores niveles de comprensión lectora en el mundoes sugerente al respecto. Se ha establecido que uno de los factores que estimula poderosamente a los estudiantes fineses para leer - 21 libros por año- es el clima de lectura, antes que los programas escolares formales. Factores como ver a sus profesores leyendo o hablando de libros, motivarse entre pares, leer en grupos por libre elección, disponer de espacios para sus comentarios y opiniones sobre las obras que han leído, y contar con interesantes programas muy bien preparados y difundidos a través de los medios de comunicación masiva ${ }^{8}$, tienen gran incidencia en el acercamiento de los estudiantes a la actividad lectora. El soporte cognitivo o desarrollo de las competencias comunicativas, y en particular de la comprensión lectora, se trabaja en el aula con estrategias metodológicas adecuadas, lo que da consistencia, coherencia y rigurosidad a todo el proceso.

\section{El DIFÍCIL RETO DE PASAR DE LA CAMPAÑA A LA REESTRUCTURACIÓN DE LAS PRÁCTICAS CULTURALES}

¿Cómo sostener en el tiempo la subjetividad lectora, que es causa y consecuencia del clima social descrito? ¿Cómo pasar de la campaña de sensibilización a la reestructuración y organización de las prácticas culturales de las personas, de manera que puedan migrar de un estado de no lectura a otro de práctica de lectura y constancia lectora? ¿Cómo evitar que estos años de fuerte inversión en la promoción y dotaciones librescas se pierdan? ¿Cómo hacer que el esfuerzo del país trascienda la novedad y el gusto intermitente por el consumo de libros, para instituir la costumbre social de la lectura? En suma, ¿cómo hacer que el deseo de leer se convierta en realidad?

Estas son algunas de las interrogantes que pueden servir para ordenar la reflexión y las próximas acciones de los diseñadores y ejecutores de la política nacional de lectura. Por nuestra parte, consideramos indispensable empezar por revisar el discurso sobre la

${ }^{8}$ España duplica a media da Unión Europea en fracaso escolar. Finlandia ten o índice máis baixo, en: La voz de Galicia, Voz Programa Prensa Escuela, Galicia, jueves 8 de diciembre de 2005 (www.lavozdegalicia.es/vozescuela). 
lectura, en términos de resignificación del concepto de leer y de la formación de su hábito. Luego, a partir de ello, analizar el desempeño de la primera agencia institucionalizada de producción social de la lectura: la escuela, que operacionaliza un discurso hasta transferirlo a la sociedad.

\section{Resignificación del concepto de lectura}

Se ha vuelto muy común hablar de la lectura. De hecho, muchas personas piensan que leer es comprender lo que dice el autor $y$ repetirlo sin variaciones, con lo cual se pierde la esencia misma del acto de leer y se corre el riesgo de fracasar en los esfuerzos por incentivarla.

Es consenso entre los investigadores de la lectura, que el núcleo de ésta actividad es el proceso de construcción protagonizado por el lector en una situación de comunicación diferida, en la que interviene la triada: lector, texto y autor (Chartier, 199910; Charmeux, $1992^{11}$; Solé $2000^{12}$; Iser $1987^{13}$, y Peña $1997^{14}$ ).

El lector construye significados y elabora sentidos en el acto de leer. La construcción de significados alude al proceso cognitivoafectivo, fisiológico y neurológico, compuesto por la utilización del conocimiento y experiencia previos, el procesamiento mental de la información, el ejercicio y control de la propia comprensión, y la conciencia de sus resultados para el mejoramiento personal.

${ }^{9}$ Es necesario prevenir que, en esta noción, el texto no se circunscribe al libro impreso, sino que refiere a un cuerpo de análisis; es decir, un objeto o lugar donde se ha producido un mensaje que toma forma y se actualiza al ser tocado por el lector. Detrás de todo mensaje se encuentra un autor o emisor, que no está visible en el texto por tratarse de un tipo de comunicación diferida, que no tiene al frente al interlocutor. Para Raffaele Simone, en «El cuerpo del texto», el libro es el contenedor físico de un cuerpo discursivo estructurado según unas leyes concretas de composición; ambas entidades son diferentes. Cf. Nunberg, Geofrey (comp.), El futuro del libro, Paidós, Barcelona, 1998, p. 243.

${ }^{10}$ Chartier, Roger, El mundo como representación, Editorial Gedisa, Barcelona, 1999, pp. 50-60.

${ }^{11}$ Charmeux, Eveline, Cómo fomentar los hábitos de lectura, Ediciones CEAC, Barcelona, 1992.

12 Solé, Isabel, Estrategias de lectura, Editorial GRAO, Barcelona, 2000.

13 Iser, Wolfganf, El acto de leer, Taurus Ediciones, Madrid, 1987.

14 Jurado Valencia, Fabio (comp.), Los procesos de la lectura, Editorial Magisterio, Santa Fé de Bogotá, 1997. 


\section{LA FORMACIÓN DEL HÁBITO LECTOR}

En principio, cada «situación concreta de lectura» ${ }^{15}$ está condicionada por el conocimiento previo del sujeto de actividad lectora, y las experiencias personales asociadas sus objetos, contenidos y escenarios (Charmeux, Heimilich y Pittelman (1991); Paris, Wison y Dikson, 1983) ${ }^{16}$. Por esta razón, un mismo libro puede generar distintos significados y sentidos para cada una de las personas que lo lee, y aún para la misma persona, si lo hace en diferentes tiempos. ${ }^{17}$

Ahora bien, el conocimiento previo de la actividad lectora está constituido, de un lado, por el equipamiento cognitivo del lector sobre las reglas de la escritura: índices linguísticos y paralinguísticos, organización de los discursos, léxico, sintaxis, gramática ${ }^{18}$, así como los saberes relacionados con los contenidos expuestos. Y, del otro lado, por el conjunto de vivencias anteriores relacionadas con los escenarios de la lectura y sus mediadores o facilitadores - hogar, escuela, librerías, bibliotecas y familiares, maestros, amigos, bibliotecarios, etcétera-.

La incidencia en la construcción de significados y elaboración de sentidos, de la capacidad del sujeto para actualizar sus conocimientos y experiencia previos durante la actividad cognoscente, ha sido demostrada y expuesta por la teoría del aprendizaje significativo que valora estos dos elementos. En efecto, Piaget considera que las acciones de los sujetos están organizadas, permanentemente, por esquemas ya formados (en el curso de su vida) que nacen de la interacción social, las condiciones orgánicas, el contacto con los objetos, y el equilibrio.

Bordieu se refiere, en el mismo sentido, al hábitus como un «sistema de esquemas adquiridos que funcionan en estado práctico como categorías de percepción y de apreciación o como principios de clasificación, al mismo tiempo, que como principios organizado-

15 Peronard T., Marian y Marisol Velásquez R., Desarrollo del conocimiento metacomprensivo, revista Signos [online] Vol. 36, No. 53 [citado el 30 de diciembre de 2005], 2003, pp.89-101. Disponible en la World Wide Web: http:/ /www.scielo.cl.

16 Citados por Peronard, Ibid. 1997.

17 Salazar, Silvana y Dante Ponce, Hábitos de Lectura, INLEC, Lima,

${ }^{18}$ Charmeux, Eveline, Cómo fomentar los hábitos de lectura, Ediciones CEAC, Barcelona, 1992, pp. 32-35. 


\section{SILVANA SALAZAR AYLLÓN}

res de la acción ${ }^{19}$. Por su parte, Bernstein utiliza la noción de código como «principio regulador, adquirido (por el sujeto) de forma tácita, que selecciona e integra: a) significados relevantes; b) formas de realización de los mismos, y c) contextos evocadores» ${ }^{20}$. En palabras de Maturana, «son las estructuras mentales, creencias e ideas que le sirven de base para interpretar objetos y eventos ${ }^{21}$.

En cuanto al procesamiento mental de la información, su realización exitosa exige haber desarrollado las capacidades y destrezas para identificar y seleccionar datos e información; comparar; relacionar; analizar; organizar; sintetizar; inferir; evaluar, y reconocer la coherencia y la cohesión de los textos. Incluye el uso de estrategias cognitivas ${ }^{22}$, como el muestreo, la predicción, inferencia, verificación y autocorrección o metacognición, que facilitan el abordaje del corpus textual. (Goodman, 1982) ${ }^{23}$.

Esto quiere decir - de acuerdo con el enfoque psicolinguístico de la lectura- que: «el sentido del texto no está en las palabras u oraciones que componen el mensaje escrito, sino en la mente del autor y en la del lector, cuando reconstruye el texto en forma significativa para élı24. Si bien el autor del texto, desde sus esquemas, se anticipa, ofreciendo los elementos de comprensión de posibles significados y guía al lector a través de la estructura textual, el significado sólo aparece cuando el texto ha sido tocado por el lector (Tierney y Pearson, 1983) ${ }^{25}$.

19 Bourdieu, Pierre, Cosas dichas, Gedisa, Barcelona, 2000, p.26.

${ }^{20}$ Bernstein, Basil, La estructura del discurso pedagógico, Ediciones Morata, Madrid, 2001, p. 27.

${ }^{21}$ Maturana 1978, 1995c, Novak 1998, Von Glasersfeld 1984, 1989, 1996, Sánchez 2001. Citado por Jaime Sánchez llabaca, «Bases constructivistas para la integración de TICs», en: Enfoques educacionales Vol.6, No. 1, Universidad de Chile, Santiago, 2004, p. 75-89.

22 Según Goodman, por muestreo el lector procesa aquellas palabras o ideas significativas para él y no todas las palabras percibidas visual o táctilmente; en síntesis, el cerebro es el que lee y no el ojo. Mediante la predicción, se construyen hipótesis relacionadas con el desarrollo y la finalización de un texto. La inferencia permite «leer entre líneas», es decir, aquello que no está explícito.

${ }^{23}$ Citado en: http://docencia.udea.edu.co/educacion/lectura_escritura/ procomposicion.html.

${ }^{24}$ Dubois, M. E., El proceso de la lectura: de la teoría a la práctica, Aique, Buenos Aires, 1991, p. 11. 


\section{LA FORMACIÓN DEL HÁBITO LECTOR}

Por lo demás, los procesos cognitivos se mezclan con el mundo de sensaciones, afectos y reacciones emocionales, movilizados por el encuentro con los mensajes durante la lectura. Esta dimensión afectiva no ha sido suficientemente reconocida y valorada por las concepciones tradicionales y por la educación.

¿Y que aporta el texto? Nunca hay que olvidar que el origen de este artefacto esencial de la lectura es la intención comunicativa del autor, la cual se encuentra presente en sus mensajes, ideas, argumentos y proposiciones, en el léxico y en la gramática utilizada, así como también en la coherencia, cohesión y consistencia argumental (Zarzosa 1992, Cassany, 1993). Ello, independientemente de su representación simbólica; se trạte de una estructura semántico-sintáctica ${ }^{26}$-como en las narraciones discursivas- o del lenguaje numérico, visual o musical -elementos a los que se ha dotado de significados intercambiables_ 27 .

De igual manera, aspectos como la organización, diagramación, las imágenes y la forma física o electrónica del soporte textual también crean sentido. Un mismo texto, presentado sin imágenes y con imágenes, puede producir distintas lecturas. De hecho, un texto en formato de libro y el mismo en formato electrónico no sólo originan construcciones diferentes en cada lector, sino que también demanda maneras de leer distintas. En internet, por ejemplo, no se pasan las páginas, se abren ventanas que conducen a nuevos textos, videos, bases de datos, otras web, etcétera.

Sin embargo, todo este proceso quedaría trunco si el lector no llega a la fase creativa, a producir nuevos ordenamientos, formular otras hipótesis, lograr elaboraciones textuales inéditas y reflexiones críticas, como parte de un proceso constructivo de su propio conocimiento, que es personal $e$ intransferible.

En resumen, la resignificación del concepto de lectura supone asumir que se trata de la construcción de significados y elaboración

${ }^{25}$ Citado por Quintana, Hilda E. La enseñanza de la comprensión lectora. Documento en línea: http://www.huascaran.edu.pe/Docentes/archivo/2004/ articulos/16-02-04ense_comlectora.doc

${ }^{26}$ Van Dijk. Citado por Celeita Reyes, Abril Lola y Pardo y Graciela Neyla, 1991 , p.187.

${ }^{27}$ Halliday, Michael A.K. El lenguaje como semiótica social. México: Fondo de Cultura Económica, 1982. 
de sentidos, a partir de los dos esquemas implicados; el del lector -que nace de sus experiencias previas y afectividad-y el del autor -que aparece en el texto-. El lector realiza el procesamiento mental de la información, monitorea y autorregula su comprensión, construye su propio conocimiento, y es conciente de los resultados de la actividad. Desde esta perspectiva, los resultados de la lectura no se miden por la cantidad de los libros leídos o el número de horas dedicadas a su práctica, sino en cómo y cuánto se ha transformado el sujeto gracias a sus lecturas, cómo ha enriquecido su mundo interior, y mejorado su actuación personal y la calidad de sus sueños de futuro.

Resignificar el concepto de lectura permite comprender las dimensiones e implicancias de su gestión en el ámbito educativo y en el ámbito social. Conduce a centrarse en los procesos internos de las personas, en el desarrollo de sus estructuras cognitivas - habilidades, capacidades, competencias-, sus motivaciones, actitudes y voluntad, y en contextos sociales y culturales específicos cuya dinámica genera predisposiciones, aún antes de que el sujeto haya conocido el libro y aprendido a leer.

\section{LA FORMACIÓN DEL HÁBITO LECTOR}

Hábito es un término que se asocia comúnmente a la repetición mecánica, autómata o inconsciente de una conducta. Si bien es cierto, el hábito supone cierto nivel de automatismo en algunos procesos, su formación demanda elevados niveles conciencia, voluntad y afectividad. Covey define el «hábito como una intersección de conocimiento, capacidad y deseo. El conocimiento es el paradigma teórico; el qué hacer y el porqué, la capacidad es el cómo hacer. Y el deseo es la motivación, el querer hacer. $)^{28}$

Sin embargo, tanto el conocimiento que implica un saber leer, como la capacidad, que supone movilizarse con soltura en el mundo de la lectura y sus objetos, pueden existir sin generar el hábito lector. Es el tercer elemento, el deseo o el querer leer, el que marca la dife-

${ }^{28}$ Covey, Stephen R., Los siete hábitos de la gente altamente efectiva, Paidós, Buenos Aires, 2004. p. 59. 


\section{LA FORMACIÓN DEL HÁBITO LECTOR}

rencia entre los lectores habituados y los no lectores. El deseo de leer es el factor más poderoso para generar hábitos de lectura y nace de asociar esta actividad al placer, a la satisfacción, a la sensación de logro y al entretenimiento. Muchas personas saben leer y tienen libros a disposición, pero no desean leer, entonces no se produce la lectura ${ }^{29}$.

En efecto, el deseo de leer es el componente productor y legitimador del hábito (Covey, Bustamante ${ }^{30}$, Salazar). El placer imaginado, como resultado de la lectura, genera emoción y deseo, que se convierte en urgencia y predispone al sujeto a transitar por el mundo de los textos y su ecosistema. Ante el deseo, las demandas ajenas, la obligación y las dificultades desaparecen; sin deseo, las lecturas son mediocres y su destino inexorable es el olvido. ${ }^{31}$

Bourdieu se refiere a la existencia de una lectura idólatra como un placer puro, que se vive como «simple placer de jugar, de jugar bien el juego cultural, de jugar con el arte de jugar, de cultivar ese placer que 'cultiva' y del que se nutre: alusiones sutiles, referencias deferentes e irreverentes, comparaciones esperadas o insólitas, etecétera» "2. Para Caivano, "el primer aspecto relacionado con el acto de leer tiene que ver con el deseo de leer. No hay aprendizajes duraderos y significativos que no se sustenten en el deseo. Sin la energía del deseo solo quedan las ruinas de algunas habilidades inconexas. Esa energía es innata en el bebé y en los primeros años de su intensísima «exploración» del entorno.

Es más, el aprendizaje de la lengua tiene como motor principal ese deseo difuso de saber, de imitar y de establecer relaciones entre sonidos, signos, personas y cosas. Nombrar el mundo es la primera forma de lectura. Esta premisa del deseo, como chispa que

${ }^{29}$ Salazar A., Silvana, Guía de gestión de centros de recursos educativos, Lima, Minedu, 2005.

${ }^{30}$ Bustamante Z., Guillermo. "Notas sobre la lectura y la escritura», en: Jurado Valencia, Fabio (comp.), Los procesos de la lectura, hacia la producción interactiva de los sentidos, Cooperativa Editorial Magisterio, Santa Fé de Bogotá, 1997, p. 132.

31 Salazar, Silvana, Hacia la construcción de nuevos paradigmas en la bibliotecología: la lectura, Informe Profesional, EAP de Bibliotecología y Ciencias de la Información, de la UNMSM, Lima, 2000.

32 Bourdieu, P., Ibid., p. 510. 


\section{SILVANA SALAZAR AYLLÓN}

enciende el interés por saber más, vale para todos los aprendizajes, y en especial para el aprendizaje de la lectura y para su ejercicio. Conviene no confundir ese deseo con sus sucedáneos pedagógico-didácticos: el «interés del niño/niña»; la «motivación»; los ejercicios de «estímulo" y una gama amplia de tentativas de reanimación lectora.»"

Desde el psicoanálisis, Petit también advierte sobre el riesgo de confundir deseo y necesidad y, peor aún, de reducir deseo a necesidad, con lo cual se producen personas anoréxicas de lectura. Afirma que los escritores más leídos por los jóvenes son aquellos que realizan sus obras «dejándose trabajar por su propio deseo», de modo que se establece una comunicación de inconsciente a inconsciente entre el autor y el lector. ${ }^{34}$

Se puede afirmar que el deseo de leer es la manifestación del gusto por la lectura; esa disposición o inclinación básica, que hace que el sujeto incurra con frecuencia en el acto de leer, para lo cual realiza acciones de selección y adquisición de objetos como libros, revistas, internet; busca espacios y tiempos para leer, $y$ tiende a preferir la interacción con sus pares lectores.

Bourdieu, en su estudio sobre el gusto ${ }^{35}$, afirma que: «la manifestación, aparentemente, más libre de un sujeto, el gusto o, mejor, las categorías de percepción de lo bello, se dan como resultado del modo en que la vida de cada sujeto se adapta a las posibilidades estilísticas ofrecidas por su condición de clase». Denomina hábitus a los condicionamientos inconscientes que operan en las prácticas individuales, como principios de percepción y apreciación.

No se trata - de acuerdo con la teoría del sociólogo francés- de una serie azarosa de inclinaciones, sino de «sistemas de disposiciones duraderas y transferibles, estructuras estructuradas y predispuestas para funcionar como estructuras estructurantes, es decir, como principios generadores y organizadores de prácticas y representaciones que pueden estar objetivamente adaptadas a su fin, sin

${ }^{33}$ Caivano, Fabricio, "Los nuevos lectores del siglo XXI», en: La educación lectora, Fundación Germán Sánchez Ruipérez, 2001, Madrid, pp. 181-196.

${ }^{34}$ Petit, Michele, Lecturas: del espacio íntimo al espacio público, Fondo de Cultura Económica, México, D. F., 2001, pp. 26-27.

${ }^{35}$ Bourdieu, P., La distinción, criterios y bases sociales del gusto, Grupo Santillana, Madrid, 2000. 


\section{LA FORMACIÓN DEL HÁBITO LECTOR}

suponer la búsqueda consciente de fines y el dominio expreso de las operaciones necesarias para alcanzarlos, objetivamente 'reguladas' y 'regulares', sin ser el producto de la obediencia a reglas $y$, a la vez que todo esto, colectivamente orquestadas, sin ser el producto de la acción organizadora de un director de orquesta.. ${ }^{36}$

El gusto es, pues, una inclinación básica inconciente, estructurada en el interior del sujeto por el grupo de referencia más inmediato - familia, comunidad-, que le hace desear y seleccionar determinados objetos, propiedades y prácticas porque le resultan «naturales». El gusto se expresa en la elección de determinados deportes, comidas, libros, vestuario, lugares de recreación, entre otros.

La formación del gusto por la lectura tiene como base la experiencia comunicativa acumulada por el sujeto. Esto ocurre desde la más temprana edad. En realidad, las primeras lecturas del ser humano —construcción de significados y elaboración de sentidos de los mensajes - las realiza en el rostro de la madre, en su mirada y su sonrisa, en sus gestos; es decir, en el desarrollo del proceso comunicativo. En el primer año de vida, hay una rica interacción entre padres e hijos: los contactos oculares, las expresiones faciales, junto con las vocalizaciones, constituyen un aspecto esencial de la interacción padres-niños en esta fase del desarrollo. (Vigotsky, 1978; Bruner, $1975^{37}$, Caivano).

En adelante, «todo lo que rodea al niño; los objetos, las personas, la situaciones, el modo como se relacionan las personas con los objetos y las personas entre sí, las secuencias temporales, la organización de los espacios y la forma como se transita por ellos o cómo se les utiliza, las formas de comunicación, las vivencias que tiene, los problemas que resuelve y cómo los resuelve, lo que mira y lo que no ve, su forma de explicar, pedir, de negarse, las cosas que memoriza, es decir, todo aquello que constituye su relación con el mundo, va configurando también su relación con la lectura. Hacia

36 «Consumo cultural y percepción estética: conceptos básicos en la obra de Pierre Bourdieu/Mariana Maestri", en Antorposmoderno. Anuario del Departamento de Ciencias de la Comunicación (http://www.fcpolit.unr.edu.ar/ a2_consumo.htm).

37 Citados por Triadó, Carmen. Adquisición y desarrollo del lenguaje. En: Desarrollo cognitivo / Editor Vicente Bermejo. Madrid, Editorial Síntesis. pp. 275-276. 


\section{SILVANA SALAZAR AYLLÓN}

los tres años ya tiene esquemas de las situaciones, a los seis ha aumentado la organización de su pensamiento, sus esquemas son más articulados, flexibles y conscientes y memoriza durante más tiempo» ${ }^{38}$.

En realidad, el proceso central de la lectura -que es la construcción de significados y elaboración de sentidos- se hace todo el tiempo en la interacción social; la cuestión es cómo transferir estas operaciones al tratamiento de los mensajes que aparecen en objetos de la lectura: libros, revistas, imágenes, etcétera.

Gusto y hábito son dos cosas diferentes. Mientras el gusto por la lectura se manifiesta en la simpatía por todo lo escrito, en ese estado de alerta hacia las novedades bibliográficas, y en la debilidad del compromiso personal y planificado con la actividad —razón por la cual a veces se lee y a veces no-; por el contrario, el hábito supone el trabajo conciente del sujeto sobre sus propios actos de leer y la interacción con el mundo y los objetos relacionados. Sin duda, el hábito es una construcción facilitada por el gusto -que determina la familiaridad y las inclinaciones básicas-; pero requiere de la voluntad, de la fijación de objetivos claros y la estructuración de procesos mediados.

Se puede afirmar que el gusto es el eslabón previo, deseable para formar el hábito de lectura, pero incurriríamos en algún grado de determinismo, si pensamos que las personas provenientes de grupos sociales, poco familiarizados con la lectura y los libros -que no han formado el gusto específico por el leer-, no pueden convertirse en lectores habituados. Sostenemos, y de hecho la investigación psicológica ${ }^{39}$ y la experiencia así lo demuestran, que es posible reestruc-

38 Domínguez, Pilar. Desarrollo de la lectura y escritura. En: Desarrollo cognitivo / Editor Vicente Bermejo. Madrid, Editorial Síntesis, 2003. pp. 377-378.

${ }^{39}$ En materia de lectura, existen opiniones muy difundidas en el sistema educativo, en el sentido que si no se forman los hábitos de lectura durante la infancia, la batalla está perdida, que no hay mucho que hacer en la secundaria, y mucho menos en la edad adulta. La inteligencia está constituida por dos grupos de habilidades importantes - la inteligencia fluida y la inteligencia cristalizada- y tiene una evolución en la vida adulta -especialmente, la cristalizada, que es donde se ubicarían las rutinas de la lectura-. La inteligencia cristalizada tiene que ver con los sistemas de conocimiento, de hecho o procedimental, asociado a las destrezas: Esto significa que es posible proponerse formar hábitos de lectura en cualquier 


\section{LA FORMACIÓN DEL HÁBITO LECTOR}

turar las prácticas sociales y formar nuevos hábitos a través de la gestión cultural, con programas debidamente diseñados, formalizados y desarrollados.

Pero, ¿cómo se forma el hábito lector? Esta es una cuestión que, al parecer, todavía no se ha resuelto, a pesar de las múltiples investigaciones y de toda la literatura producida en su nombre. "Los hábitos de lectura son más complejos de estudiar que todos los demás. La observación directa del comportamiento no revela más que la postura y no el acto de lectura, del que no es más que la apariencia, a menudo engañosa. La estadística no proporciona datos más que sobre el volumen, el ritmo, la inserción social de un consumo de documentos impresos, que no significan necesariamente lectura.. ${ }^{40}$ Sin embargo, y en uso de la licencia que otorga un tema en discusión como éste, compartimos nuestras indagaciones y reflexiones.

Los hallazgos del estudio exploratorio de hábitos de lectura ${ }^{41}$ -realizado por el Ministerio de Educación en 95 estudiantes de la secundaria de todas las regiones del país, qúe demostraron ser lectores perseverantes y autónomos-demuestran que: 1) no existe una correlación absoluta entre padres lectores e hijos lectores; en varios casos, el hábito se forma a pesar de la incomprensión y oposición del núcleo familiar; 2) siempre hay modelos o referentes personales de lectores - familiares, amigos, maestros, etcétera- que generan percepciones favorables a la lectura, aún sin proponérselo; 3) los estudiantes con hábitos de lectura tienen definidas sus expectativas de futuro; 4) la lectura es usada por adolescentes lectores para construir su espacio íntimo y fortalecer su identidad, y 5) los estudiantes prefieren leer en la intimidad de su hogar, que en la escuela.

etapa de la vida, considerando que el hábito de lectura tiene componentes mecánicos y voluntarios. Al respecto, la perspectiva del ciclo vital en la psicología sirve para darle una nueva mirada a la formación de hábitos de lectura en las personas adultas. Véase: Serra Desfilis, Emilia, «Perspectiva del ciclo vital», en: Bermejo, V. (ed.), Desarrollo cognitivo, Editorial Síntesis, Madrid, 2003, pp. 110-113.

${ }^{40}$ Barrer, Ronald y Robert Escarpit, El deseo de leer, Barcelona, 1974, p. 152.

${ }^{41}$ Realizado por Silvana Salazar y Julio Mendoza, en el marco de la ejecución del Plan Lector de la Dirección Nacional de Educación Secundaria y Superior Tecnológica, del Ministerio de Educación. 
Para ilustrar estas afirmaciones, transcribimos algunos de los testimonios ${ }^{42}$ recogidos en los nueve grupos focales que se realizaron para la investigación:

María Luisa (16 años): «En el caso mío, en mi casa, a mis padres no les gusta leer. Somos siete hermanos; algunos de mis hermanos son profesionales. A mis hermanas no, a ninguna le gusta leer, yo soy la única que le gusta leer, a mi hermano menor no le gusta.»

Haydée (14 años): «Me gusta leer más que todo a partir de las 10 de la noche, en mi casa, hasta las 2 de la mañana. Mi mamá me dice que apague la luz - estás fastidiando, tu papá está descansando, que tiene que dormir, ¿por qué te pones a estudiar tarde? - La verdad, no sé por qué mi mamá siempre dice: pierdes tu tiempo.»

Hans (15 años): «A mí me gusta leer en las noches y también en la tarde, y donde hay bulla para poder contrastar mi voz con la bulla, para hacer competencia a ver quién gana. Por ejemplo, cuando yo me voy a mi huerta, mi mamá está que riega mis plantas y tengo un hermano que estudia y estudia fuerte, y yo leo fuerte para hacer ganadas (competencia). Y siempre hago así, cuando voy al río también trato de ganarle al sonido del río.»

Sobre el papel de la lectura en la construcción del espacio propio por los adolescentes, Petit es enfática: «Este espacio creado por la lectura no es una ilusión. Es un espacio psíquico que puede ser el sitio mismo de la elaboración, o la reconquista de una posición del sujeto... Los adolescentes acuden a los libros, en primer lugar, para explorar los secretos del sexo, para permitir que se exprese lo más secreto, que pertenece por excelencia al dominio de las ensoñaciones eróticas, las fantasías. Van en busca, además, de palabras que les permitan domesticar sus miedos y encontrar respuestas a las preguntas que los atormentan. Indagan en distintas direcciones, sin hacer caso de rúbricas y líneas demarcatorias entre obras más o menos legítimas. ${ }^{43}$

Como en todo aprendizaje, hay que tener en cuenta que la formación del hábito lector puede ser percibida, por el sujeto, como

${ }^{42}$ Archivos de la investigación.

${ }^{43}$ Petit, M., op. cit., pp. 45-46. 


\section{LA FORMACIÓN DEL HÁBITO LECTOR}

el tránsito de un estado de incompetencia a un estado de competencia. La literatura psicopedagógica reconoce cuatro etapas que se pueden aplicar a la formación del hábito lector:

Etapa 1. De incompetencia inconsciente, que es cuando el sujeto ignora su carencia y tampoco tiene experiencia alguna al respecto. En lectura, podemos referirnos a las personas que forman parte de familias y comunidades poco relacionadas con el mundo de lo escrito ${ }^{44}$ - a quienes le son extraños el libro y la lectura-, y los niños que todavía no han ingresado a la escolaridad. Se trata de la 'ignorancia dichosa'. En esta etapa, un plan de formación de hábitos tendría que considerar, como tarea central, la identificación de factores favorables a la lectura en los gustos, costumbres y predisposiciones básicas de los sujetos -elementos facilitadores de su cultura de origen que hacen el papel de anclas en la formación del hábito lector-.

Etapa 2. De incompetencia consciente. Generalmente, al inicio y durante la escolaridad, se hace conciente para todos los niños $y$ adolescentes la necesidad de leer, $y$ aparecen las dificultades $e$ incomodidades, de carácter cognitivo y afectivo, que generan avances y retrocesos. Para los jóvenes y adultos, que han finalizado su ciclo de educación institucionalizada y no tienen exigencias formales de lectura, este estado de incompetencia consciente está presente como culpa ${ }^{45}$ por no leer frecuentemente, debido a que «la mayoría de las personas son concientes de la importancia y finalidad de la lectura, han aprendido a leer; pero, saber leer no basta para adquirir el hábito de lectura, para ello hay que pasar por un aprendizaje organizado y sistemático». ${ }^{46}$

${ }^{44}$ Michele Petit informa que «en los ámbitos donde impera una economía de subsistencia, alguien puede sentirse culpable de leer, ya que es una actividad cuya 'utilidad' no está bien definida; también puede sentirse culpable porque para leer se aísla, se retira del grupo... Es una actividad, a menudo, mal recibida en los medios populares, donde se valoran más las actividades compartidas y donde no se dispone de tiempo ni de espacio para sí mismo. Cf. Petit, M., op. cit., p. 25. Véase siguiente nota.

45 Un interesante trabajo de investigación sobre las personas que no leen con frecuencia es el de Joelle Bahloul, titulado Lecturas precarias, estudios sociológico sobre los pocos lectores, Fondo de Cultura Económica, México, D. F., 2002. Véase nota anterior.

${ }^{46}$ Salazar A., S. y Ponce, D., op. cit., p. 62. 


\section{SILVANA SALAZAR AYLLÓN}

En esta etapa es indispensable la aplicación de los principios del aprendizaje mediado: intencionalidad, trascendencia y significado. No debemos confundir el propósito de mejorar la comprensión lectora con el de formar el hábito lector; tampoco, reducir el valor de la actividad a su función utilitaria e instrumental (cumplimiento académico o laboral), ni despojarla de su valor afectivo.

De otro lado, con el desarrollo de las tecnologías de la información y la comunicación, ha surgido una categoría de aprendizajes orientados a lograr que las personas puedan moverse con facilidad $y$ éxito en el ecosistema social y artificial ${ }^{47}$ de la lectura: buscadores de internet, fuentes de información, bibliotecas, bases de datos, librerías y materiales de lectura en distintos soportes, entre otros; nos referimos al desarrollo de las habilidades informativas ${ }^{48}$. Se trata de apoyar a las personas para que puedan cubrir el espacio que existe entre el deseo de leer y los objetos y escenarios de la lectura. Salazar y Ponce denominan «fase informativa» al proceso de familiarización con la actividad, sus objetos y ambiente. ${ }^{49}$

Etapa 3. De competencia consciente. Es el resultado de los avances en la formación del hábito; aparece la sensación de logro y el placer cada vez que hay éxito, la conciencia de que se está avanzando y que este resultado implica atención, concentración, perseverancia en la acción y autoevaluación. Aquí ya puede observarse el cumplimiento de las secuencias básicas del comportamiento lector: establecer la finalidad de la lectura; elegir el texto preciso; seleccionar y aplicar técnicas y estrategias conforme a los objetivos de la lectura y al tipo de material; satisfacer las exigencias del nivel de lectura, modular los ritmos y tiempos; controlar la tensión y la fati-

47 Teun A. Van Dijk propone la existencia de una disciplina transversal que estaría encargada de integrar los diversos aspectos de la producción; la comprensión y el efecto de los textos, así como sus relaciones con el contexto. En: Van Dijk, Teun A., La ciencia del texto, un enfoque interdisciplinario, Paidós, Barcelona, 1997.

${ }^{48}$ Las habilidades informativas más importantes son: identificar, expresar y comunicar adecuadamente la propia necesidad de información; elaborar planes de lectura; seleccionar estrategias de búsqueda de información; organizar la información recopilada en diferentes fuentes; elaborar productos de lectura, tales como fichas, resúmenes, informes, entre otros, y utilizar diversos servicios de información. Véase: S. Salazar, op. cit., 2005.

${ }^{49}$ Salazar A., S. y D. Ponce, op. cit., p. 67. 
ga, y ejecutar correctamente las rutinas de manipulación del objeto de lectura. ${ }^{50}$

Etapa 4. De competencia inconsciente. Es cuando el hábito se ha formado; es la etapa del dominio de todo el proceso y sus partes, y de la ejecución fluida y constante. Ya no cuesta trabajo decidirse por la lectura: el sujeto se autodirige con naturalidad. Se observa la existencia de proyectos personales de lectura sobre los que trabaja por decisión propia, sin tener que dar cuenta a nadie. El sujeto elige la lectura entre otros placeres; tiene temas o autores favoritos, $y$ frecuenta lugares y personas donde vive la lectura. La voluntad de leer trasciende el imperativo social y el mandato académico o laboral.

En resumen, el hábito lector es un comportamiento estructurado - no espontáneo- que lleva a realizar, frecuentemente, esta actividad para responder siempre a motivaciones personales que contribuyen a generar satisfacción, sensación de logro, placer y entretenimiento. Los procesos concientes del hábito de lectura son: la fijación del propósito; la realización de las operaciones mentales implicadas - actualización del conocimiento y las experiencias previas, el procesamiento de la información, el control y regulación de los procesos mentales y la conciencia de sus resultados-; el uso de las habilidades informativas, y la transferencia de los resultados a otras actividades y reflexiones.

Las operaciones que pueden volverse automáticas son: la eficiencia del músculo de los ojos, el uso de técnicas de lectura rápida, la lectura mental y no subvocalizada, la manipulación física del material, etcétera. ${ }^{51}$ Asimismo, el hábito requiere $y$, a la vez, permite la creación de un espacio íntimo donde se produce la lectura, y supone el ejercicio de niveles crecientes de autonomía personal.

\section{LA PRODUCCIÓN SOCIAL DE LA LECTURA POR EL SISTEMA EDUCATIVO}

El aprendizaje de la lectura y la formación de su hábito forma parte de procesos amplios de interacción entre sujetos, y de éstos con cier-

${ }^{50}$ Salazar A., S. y D. Ponce, loc. cit., pp. 66-67.

51 Salazar, S. y D. Ponce, Ibid. 


\section{SILVANA SALAZAR AYLLÓN}

tas instituciones y escenarios; donde circulan los objetos, los productores, mediadores y facilitadores, relacionados con la práctica de la actividad. De todos ellos, la institución educativa tiene una importancia crucial; no sólo porque ahí se produce y desarrolla el aprendizaje de la lecto-escritura a lo largo de once años de la vida de las personas, sino porque también en ella se estructuran las percepciones, significados y sentidos de la actividad y sus recursos.

En efecto, el sistema educativo produce un discurso sobre la lectura que aparece formalmente en el currículo y en los documentos técnico-normativos que regulan la acción pedagógica. Este discurso oficial que establece las intenciones, es decir, los significados relevantes sobre la lectura, es acompañado por un aparato metodológico que también sale como discurso de la agencia central -Ministerio de Educación-y se refiere a las formas de aplicar y desarrollar lo que dice el currículo sobre la lectura.

Sobre la base de la resignificación del concepto de la lectura y del hábito lector propuestos, interrogamos al Diseño Curricular Nacional $2005^{52}$, y encontramos que el enfoque pedagógico, la metodología y evaluación de la lectura recogen los avances de la pedagogía, la psicología cognitiva y la psicopedagogía.

No obstante, entre los logros educativos de los estudiantes, esperados por el sistema al finalizar la Educación Básica Regular, no aparece el. hábito lector. La expectativa más cercana se enuncia como la característica de: «Investigador informado. Que busca y maneja información actualizada, significativa y diversa, de manera organizada, siendo capaz de analizarla y compararla, y de construir nuevos conocimientos a partir de ella. Hace conjeturas y se interesa por resolver diversos problemas de la vida diaria y de la ciencia, haciendo uso de las tecnologías de la información y comunicación» ${ }^{53}$. Hay que destacar que en el Área de Comunicación, en el detalle de los logros de aprendizaje por ciclos y niveles, se valora la dimensión afectiva de la lectura.

Sin embargo, la formación del hábito lector está ausente en el discurso curricular; el sistema educativo no se fija como propósito Lima, 2005.

52 Ministerio de Educación del Perú, Diseño Curricular Nacional 2005,

${ }^{53}$ Ministerio de Educación del Perú, loc. cit., p. 17. 
formar el hábito lector en los estudiantes. Para Caivano, «Saber leer no es tener una educación lectora. Leer tiene poco que ver con la educación lectora. Se ha producido un error de perspectiva. Una cosa es aprender en un contexto escolar las destrezas mínimas para saber leer, y otra muy distinta es aplicar esa habilidad con autonomía y gustos propios en otros contextos no escolares. De hecho, es el mismo error de perspectiva que hace que los saberes escolares no tengan significatividad en otros contextos. La escuela, sin duda, enseña, pero buena parte de sus enseñanzas provocan aprendizajes de inmediata y limitada aplicación escolar. Saber matemáticas es un saber para la escuela; saber leer es un saber central, puesto que da acceso a los demás saberes curriculares. La educación lectora implica necesariamente saber leer, pero no a la inversa. Se puede saber leer y no tener la menor educación lectora. Educación lectora no quiere decir simplemente leer, sino tener un gusto literario formado $y$ desarrollar estrategias lectoras de calidad. „54

El enfoque por competencias y capacidades del currículo direcciona el desarrollo curricular hacia las estrategias de comprensión lectora ${ }^{55}$, como aspecto clave de la competencia comunicativa y del acceso a otros saberes. Pero, el dominio de la comprensión lectora no conduce, en forma automática, a la formación del hábito lector. «El conocimiento acreditado de las reglas del discurso, plasmado en los distintos hábeas textuales (frase nuestra), es una cosa; y su puesta en práctica en un contexto local, otra muy distinta. Por tanto, el conocimiento de las reglas no facilita, necesariamente el conocimiento de su uso contextual» ${ }^{56}$.

Esto es, si bien el desarrollo de la comprensión lectora es un objetivo válido para conocer las reglas de funcionamiento de la lengua, para comprender lo que se lee, no necesariamente asegura la práctica sistemática y estructurada de la lectura por los estudiantes, no sólo dentro; sino, especialmente, fuera de la institución educativa.

${ }^{54}$ Caivano, F., op. cit., pp. 181-196.

${ }^{55}$ Respecto al tratamiento de la comprensión lectora, Isabel Solé realiza interesantes observaciones al trabajo pedagógico en su libro Estrategias de lectura, op. cit.

${ }^{56}$ Bernstein, B., op. cit., p. 35 
Al no explicitarse en las intenciones educativas la formación del hábito lector, se puede pensar que o los diseñadores no admiten como válido que el estudiante alcance esta competencia, o que se espera su logro como un subproducto implícito del desarrollo de la comprensión lectora. Ello explica por qué, respecto al hábito lector, no encontramos en el discurso pedagógico oficial los supuestos del aprendizaje mediado, que son:

a) Intencionalidad. No aparece entre los rasgos deseables del estudiante, al concluir su formación, haber desarrollado el hábito de lectura. En los currículos, no hay nada explícito sobre la formación de hábitos de lectura.

b) Trascendencia. El tratamiento de la lectura tiene como horizonte central su aprendizaje, el desarrollo de las capacidades específicas de la comprensión lectora junto con las otras capacidades de la comunicación: la producción de textos y la expresión y apreciación artística. No existe una planificación para formar hábitos. Las áreas curriculares no han sido diseñadas de manera que la lectura, que es transversal, se articule con las actitudes y valores para llevar al estudiante a proyectarse a una meta más elevada, como es el hábito lector.

c) Significado. La naturaleza y valor afectivo de la lectura tienen un reconocimiento formal, pero en las orientaciones para su operativización en los currículos por nivel educativo, no hay lugar para las construcciones del espacio íntimo y la autonomía, asociadas a la lectura, ni la intención explícita de garantizar la sensación de logro y el placer en los educandos.

En consecuencia, la formación del hábito lector es el resultado de una intencionalidad explícita que, a su vez, conduce a una intervención planificada y sistemática —donde el sistema selecciona los estímulos del medio, los organiza y estructura en función a esta meta específica; y genera interacciones y crea un clima favorable para que el estudiante pueda responder con lectura a situaciones diversas que van más allá de las necesidades inmediatas de la tarea escolar-. Si estos elementos no aparecen en el diseño pedagógico, entonces, la educación no ha previsto un trabajo de mediación con este propósito; por tanto, no se propone formar hábitos de lectura.

En el plano de la gestión y de la práctica pedagógica concreta, los vacíos del discurso oficial generan otros discursos y respuestas 


\section{LA FORMACIÓN DEL HÁBITO LECTOR}

en el sistema educativo y en la sociedad. Por ejemplo, es indiscutible que la movilización nacional por la Emergencia Educativa -decretada por el gobierno hace tres años-y la intensa labor de Promolibro y la Biblioteca Nacional, han logrado colocar el tema de la lectura en la preocupación cotidiana de las personas e instituciones del sector - como evidencia del clima social de lectura-.

No obstante, no queda claro el objetivo, al menos no en los múltiples discursos generados en el proceso. Para unos, el propósito mayor es resolver las deficiencias de la comprensión lectora; para otros, se trata de formar hábitos de lectura, y hay quienes plantean, como intención mayor, dinamizar y enriquecer las prácticas y consumos culturales de la población.

En todo caso, la necesidad de formar hábitos se respira, pero no alcanza a constituir un discurso basado en una racionalidad clara, que se concrete en programas y planes estructrurados y financiados.

En el sector educativo, las instituciones educativas, presionadas, de un lado, por el Ministerio de Educación y su aparato de gestión $y$, del otro, por los padres de familia y la comunidad en su conjunto, tienen que mostrar avances y resultados en el desarrollo de la lectura. En realidad, es aquí donde se establecen las reglas de ejecución y realización pedagógica ${ }^{57}$ de la lectura y su hábito, más allá de las intenciones de las autoridades nacionales. El verdadero aparato de producción de lectura lo constituyen las instituciones educativas de base, sobre las cuales los creadores del discurso pedagógico tienen muy poco poder.

En efecto, la práctica pedagógica cotidiana resignifica la lectura en todos sus extremos, a nivel de las intenciones; en el plano metodológico, y de manera más determinante, al crear contextos y climas específicos para su desarrollo o supresión. ${ }^{58}$ En el ámbito es-

${ }^{57}$ Bernstein considera que la escuela es una agencia de control simbólico, especializada en construir un discurso que comprende modos de relacionar, pensar y sentir, formas de conciencia, interacciones sociales y disposiciones, asociadas a las relaciones de poder prevalecientes. Ibid, pp. 139-144.

58 Trabajamos con el concepto de código de Bernstein. Un código es un principio regulador, adquirido de forma tácita, que selecciona e integra: a) significados relevantes; b) formas de realización de los mismos, y c) contextos evocadores. 


\section{SILVANA SALAZAR AYLLÓN}

colar, se configura una red de significados relevantes y formas de realización de la lectura claramente identificables en: a) las interacciones entre docentes $y$ estudiantes, $y$ b) las condiciones materiales $y$ de accesibilidad a los recursos informativos.

$\mathrm{El}$ análisis de estos dos elementos - las interacciones entre los sujetos y las condiciones materiales para la lectura ${ }^{59}$ - permite deducir el tipo de discurso implícito, construido por cada escuela sobre la lectura ${ }^{60}$.

a) Interacciones sobre la lectura

Son las relaciones de sentido entre los actores del proceso pedagógico, que van más allá del discurso formal sobre la importancia y función de la lectura. Están asociadas a un discurso de base - hábitus en Bourdieu; códigos en Bernstein, y estructuras mentales en Maturana-, del que son portadores o reproductores los directores, docentes, estudiantes y familias. La naturaleza y orientación de las interacciones producidas en la escuela, en torno a la lectura y su práctica, se pueden observar en:

- El peso asignado al desarrollo de la comprensión lectora y al hábito lector en la promoción de un grado a otro.

- Relación entre las acciones orientadas al desarrollo de la comprensión lectora y las acciones para la formación del hábito de lectura.

- La práctica lectora del docente. Trato que da la institución educativa a los docentes apasionados por la lectura.

59 Tomamos de Bernstein los principios «interactivo» $y$ «de situación» que regulan la elaboración del discurso pedagógico, sus códigos, modalidades y reproducción. Ibid., pp. 46-47.

60 Pueden revisarse los estudios realizados por GRADE y el IEP en las escuelas públicas peruanas. El primero se titula Las actitudes de los estudiantes peruanos hacia la lectura, la escritura, la matemática y las lenguas indígenas, y fue realizado por Santiago Cueto, Fernando Andrade y Juan León, GRADE Lima, 2003. El otro estudio, Recursos desarticulados, el uso de textos en la escuela pública, fue hecho por Mariana Eguren, Carolina de Belaunde y Natalia González, IEP, Lima, 2005. 


\section{LA FORMACIÓN DEL HÁBITO LECTOR}

- Las actividades orientadas a promover la lectura entre los docentes.

- La práctica pedagógica, asociada a la construcción de la autonomía del estudiante, para «aprender a aprender» mediante el ejercicio de la lectura.

- Las estrategias orientadas a generar sensación de logro en los estudiantes por sus trabajos de lectura. Revisión exhaustiva de asignaciones y monografías, y anotaciones de reconocimiento.

- Las relaciones entre la lectura funcional y la recreativa en el discurso y la práctica pedagógica.

- El reconocimiento y lugar que ocupa el fomento de la lectura de placer en la institución educativa.

- El interés por la dimensión afectiva de las lecturas.

- La relación entre el fomento del prestigio de la lectura y las acciones para facilitar la lectura real.

- La actitud del docente ante las dudas y vacíos de carácter informativo formuladas planteadas por los estudiantes.

- Cómo se valora y usa el conocimiento previo, basado en fuentes de información.

- La actitud del docente frente al uso de la internet por los estudiantes.

- ¿Qué hace el docente cuando encuentra estudiantes bien informados?

- Ejercicio de la lectura en distintos soportes: libros, audiovisuales, internet.

- Características del acompañamiento y revisión de los trabajos grupales y personales de los estudiantes.

- Formas de comunicación e interacción entre docentes.

- Interacciones entre la escuela y la comunidad en función a la lectura escolar.

- Calidad del uso de los espacios asignados a las bibliotecas: ¿lugares de castigo o espacios de ejercicio de la comunicación y autonomía?

- Los compromisos entre la institución educativa y las familias para atender los intereses y necesidades lectoras de los estudiantes. 


\section{SILVANA SALAZAR AYLLÓN}

- Los estudios e indagaciones sobre los intereses y gustos culturales de los estudiantes y docentes.

\section{b) Condiciones materiales o «de situación»}

Es el conjunto de recursos materiales y metodológicos que facilitan la práctica de la lectura más allá del aula. Es decir, los objetos, formas de organización, instrumentos y procedimientos que usa la institución educativa para garantizar la accesibilidad a la información, y el uso óptimo de los recursos para la lectura por los estudiantes y docentes. Para descubrir el verdadero discurso sobre la lectura en la institución educativa, hay que analizar los siguientes aspectos:

- Disponibilidad de recursos educativos e informativos: libros y todo tipo de impresos, materiales audiovisuales, informáticos, equipos de laboratorio y manipulativos, bases de datos.

- Calidad y cantidad de materiales y recursos informativos que se usan en el aula, adquiridos o producidos por docentes $y$ estudiantes.

- Niveles de accesibilidad a la información; organización técnica de los recursos; catalogación, índices temáticos y sistemáticos, poligrafías, ficheros, sistemas de recuperación de información.

- Espacios físicos y diseño de servicios para la lectura recreativa y la lectura funcional.

- Lugares y espacios donde los estudiantes puedan compartir sus lecturas.

- Estrategias metodológicas para desarrollar habilidades informativas.

- Características y funciones de las colecciones y recursos.

- Porcentaje del presupuesto destinado a materiales de lectura, y equipamiento para bibliotecas y centros de recursos educativos.

- Asignación de espacios físicos y equipamiento para la lectura.

- Perfil del personal asignado para atender servicios de lectura.

- Modelo de gestión de la información y los recursos educativos. 
Estos dos factores - las interacciones y las condiciones materiales sobre y para la lectura- expresan la concepción generada por la institución educativa, la cual va a modular la formación lectora de los estudiantes. Aunque el margen de elaboración y acción de la institución educativa es bastante amplio, a nivel del discurso y las interacciones, los límites están dados por los recursos, la capacidad de gestión y la disponibilidad presupuestal.

De otro lado, las combinaciones de las interacciones sobre la lectura, así como las condiciones materiales o de situación - gestión de los recursos e insumos que le sirven-, generan diversos modelos de gestión, que son respuestas organizativas frente a los retos de mejorar la lectura escolar e inștalar el hábito lector. Es un asunto de paradigmas porque una cosa es gestionar los insumos de la lectura, que son los libros y textos en sus diversos soportes: impresos, visuales, audiovisuales, electrónicos, etcétera, y otra muy distinta es gestionar la lectura.

Hay que reconocer que el paradigma de base de las bibliotecas $^{61}$ gira en torno al mundo del libro y su organización: selección, procesamiento técnico, recuperación de la información y servicios en torno a colecciones bibliográficas y documentales, antes que en la gestión de la lectura propiamente dicha y menos aún en la formación de su hábito. Ello implicaría centrarse en los procesos internos de las personas, en el desarrollo de sus estructuras cognitivas habilidades, capacidades, competencias-, sus motivaciones, actitudes y voluntad, en contextos sociales y culturales específicos, que forman el gusto y los hábitos de consumo.

Un avance significativo en la superación de las concepciones tradicionales de gestión de las bibliotecas es la creación de los Centros de Recursos para el Aprendizaje, Centros de Recursos Educativos, y Bancos del Libro, que aplican el enfoque curricular y generan articulaciones entre la gestión pedagógica y la gestión de la lectura -intereses y necesidades de los usuarios-, así como el involucramiento de docentes y estudiantes en el la planificación, ejecución y evaluación de los servicios.

Respecto a las interacciones con el entorno comunitario y social, las instituciones educativas operan más por intuición que so-

${ }^{61}$ Salazar, S., op. cit., 2000. 


\section{SILVANA SALAZAR AYLLÓN}

bre la base de una racionalidad elaborada. Por ejemplo, los grandes colegios particulares —que son los que están mejor implementados y que atienden a sectores económicos de gran capacidad adquisitiva- tienen bibliotecas que sólo complementan los múltiples recursos disponibles para sus estudiantes en el mundo familiar y en su entorno social. Las familias a las que atienden cuentan con libros, cable, internet, y todo tipo de recursos para el aprendizaje y la recreación. Una biblioteca escolar, en este escenario, no necesita más que tributar a la función curricular, a los contenidos previstos en las distintas unidades de aprendizaje de las matemáticas, comunicación, ciencias sociales, ciencias, tecnología y ambiente, etcétera.

No es igual en los colegios del estado, donde la biblioteca si existe-casi siempre es el primer y único espacio organizado de libros y otros materiales, al que acceden los estudiantes que, por lo general, son hijos de familias que están por debajo de la línea de pobreza. En estos escenarios, la biblioteca enfrenta el desafío de generar equidad, es decir, de compensar las carencias de entrada de los estudiantes, relacionadas con el desconocimiento, o mínimo acceso y uso de este tipo de objetos culturales para el aprendizaje y la recreación.

La gestión educativa tiene que ser conciente que el libro, la revista, el video, el CD, la internet, no forman parte de la vida cotidiana de los estudiantes de estos sectores y que, por tanto, su acercamiento a ellos exige un tipo de mediación que considere desde la percepción sensorial hasta su aprehensión total.

El imperativo de la equidad tendría que enriquecer las colecciones de las bibliotecas escolares a fin de que no se restrinjan a los textos escolares y recursos útiles para el trabajo obligatorio de los temas curriculares; sino, y sobre todo, dotarlas de materiales para la recreación, el esparcimiento y el placer, que son la base de la lectura autónoma y perseverante.

Finalmente, dado que la educación marca la vida de las personas, no se puede despreciar once años para construir una buena relación con la lectura. Debemos reconocer que la escuela está forjando, permanentemente, un tipo de experiencia previa asociada a la lectura. Así como la investigación demuestra que los primeros cuentos leídos en un clima de afecto y alegría forjan lectores a futuro, también es cierto que convertir las tareas de lectura en castigo, o 


\section{LA FORMACIÓN DEL HÁBITO LECTOR}

utilizar las instalaciones de la biblioteca escolar como centro de reclusión o castigo para los alumnos que cometen infracciones, va generando un discurso negativo que se instala, irremediablemente, en la conciencia del estudiante. Y esa percepción alimenta su experiencia y conocimiento previo sobre la actividad lectora, en su vida posterior de joven y adulto. 


\section{BIBLIOGRAFÍA}

BAHLOUL, Joelle

2002 Lecturas precarias: estudio antropológico sobre los "poco lectores", Fondo de Cultura Económica (Espacios de lectura), México, D. F., 163 pp.

BARRER, Ronald y Robert ESCARPIT

1974 El deseo de leer, Barcelona.

BERMEJO, Vicente

2003 Desarrollo cognitivo, Editorial Síntesis (Síntesis psicológica), Madrid, $511 \mathrm{pp}$.

BERNSTEIN, Basil

2001 La estructura del discurso pedagógico: clases, códigos y control simbólico (Tr. Pablo Manzano), Ediciones Morata (Colección: Pedagogía Educación Crítica), Madrid, 237 pp.

BOURDIEU, Pierre

1979 La distinción; criterio y bases sociales del gusto (Tr. María del Carmen Ruiz de Elvira), Santillana, Madrid, 597 pp.

2000 Cosas dichas, Gedisa, Barcelona, 199 pp.

BRUNET, $\mathrm{L}$.

1999 El clima de trabajo en las organizaciones: definiciones, diagnóstico y consecuencias, Editorial Trillas, México.

BUSTAMANTE ZAMUDIO, Guillermo y Fabio JURADO VALENCIA (compiladores)

1997 Entre la lectura y la escritura: hacia la producción interactiva de los sentidos, Cooperativa Editorial Magisterio, Santa Fé de Bogotá, 199 pp.

CASASSUS, Juan

2003 La escuela y la (des)igualdad (Prefacio de Alan Touraine), LOM Ediciones, Santiago, 214 pp. 


\section{LA FORMACIÓN DEL HÁBITO LECTOR}

CASSANY, D., M. LUNA y G. SANZ

1994 Enseñar lengua, Grao, Barcelona.

CAVALLO, Guglielmo y Roger CHARTIER (dirs.)

1998 Historia de la lectura en el mundo occidental, Santillana, Taurus, Madrid, $585 \mathrm{pp}$.

CHARMEUX, Eveline

1992 Cómo fomentar los hábitos de lectura, Ediciones CEAC, Barcelona, $156 \mathrm{pp}$.

CHARTIER, Anne-Marie y Jean HÉBRARD

1998 Discursos sobre la lectura (1880-1980), Gedisa, Barcelona, 583 pp.

CHARTIER, Roger

1996 Escribir las prácticas: Foucault, de Certeau, Marin, Manantial, Buenos Aires, 127 pp.

1999 El mundo como representación: estudios sobre historia cultural, Gedisa, Barcelona, 276 pp.

COVEY, Stephen R.

2004 Los siete hábitos de la gente altamente efectiva: la revolución ética en la vida cotidiana y en la empresa, Paidós, Buenos Aires, $384 \mathrm{pp}$.

CUETO, Santiago, FERNANDO Andrade y Juan LEÓN

2003 Las actitudes de los estudiantes peruanos hacia la lectura, la escritura, la matemática y las lenguas indígenas (Documento de trabajo 44), GRADE- Ministerio de Educación, Lima, 75 pp.

DESSLER. Gary

1993 Organización y Administración, Prentice Hall Interamericana, México, 181 pp.

DIJK, Teun A.

1997 La ciencia del texto, un enfoque interdisciplinario, Paidós, Barcelona.

DOMÍNGUEZ, Pilar

2003 «Desarrollo de la lectura y escritura», en: Vicente Bermejo (ed.), Desarrollo cognitivo, Ed. Síntesis, Madrid, pp.377-378. 


\section{SILVANA SALAZAR AYLLÓN}

DUBOIS, M. E.

1991 El proceso de la lectura: de la teoría a la práctica, Aique, Buenos Aires.

ECO, Umberto

1998 El futuro del libro: ¿esto matará eso? (Epílogo), Paidós, Barcelona, $314 \mathrm{pp}$.

EGUREN, Mariana

2005 Recursos desarticulados, el uso de textos en la escuela pública, IEP, Lima.

EGUREN Mariana, Carolina de BELAUNDE y Natalia GONZÁLEZ

2005 Recursos desarticulados: el uso de textos en la escuela pública, IEP (Colección mínima, 58), Lima, 177 pp.

FUNDACIÓN Germán Sánchez Ruipérez

2001 La educación lectora: encuentro iberoamericano, Madrid, 205 pp.

GOODMAN, K.

1982 «El proceso de lectura: consideraciones a través de las lenguas y del desarrollo", en E. Ferrero y M. Gómez Palacio, Nuevas perpectivas sobre los procesos de lectura y escritura, Siglo XXI, México.

HALLIDAY, Michael A. K.

1982 El lenguaje como semiótica social, Fondo de Cultura Económica, México.

HEIMLICH, J.E. y S.D PITTELMAN

1991 El mapa semántico, Aique, Argentina.

ISER, Wolfgang

1987 El acto de leer; teoría del efecto estético (Tr. Manuel Barbeito), Taurus, Madrid, 357 pp.

JURADO VALENCIA, Fabio y Guillermo BUSTAMANTE ZAMUDIO (comps.)

1997 Los procesos de la lectura: hacia la producción interactiva de los sentidos, Cooperativa Editorial Magisterio, Santa Fé de Bogotá, 147 pp. 


\section{LA FORMACIÓN DEL HÁBITO LECTOR}

LAINO, Dora

2000 Aspectos psicosociales del aprendizaje, Homo Sapiens Ediciones, Santa Fé, 153 pp.

MINISTERIO DE EDUCACIÓN DEL PERÚ

2005 Diseño Curricular Nacional, Minedu, Lima.

MOREIRA, Elena

2003 La gestión cultural: herramienta para la democratización de los consumos culturales, Longseller, Buenos Aires, 128 pp.

PEARSON, P.D.

1992 «Developing expertise in reading comprehension», en: S. J. Samuels \& A. E. Farstrup (eds.), What research has to say about reading instruction, 2da. ed., Ed. IRA, Newark, pp. 145-199.

PERONARD T., Marian y Marisol VELÁSQUEZ R.

2003 «Desarrollo del conocimiento metacomprensivo», Signos (online) Vol. 36, No. 53 [citado el 30 de diciembre de 2005], pp.89-101 (http://www.scielo.cl).

PETIT, Michele

2001 Lecturas: del espacio íntimo al espacio público (Tr. Miguel y Malou Paleo y Diana Luz Sánchez), Fondo de Cultura Económica (Espacios de lectura), México D. F., 178 pp.

PINZÁS G., Juana

1997 Metacognición y lectura, Fondo Editorial de la PUCP, Lima, $135 \mathrm{pp}$.

PITTELMAN, Susan D., Joan E. HEIMLICH, Roberta L. BERGLUND y Michael P. FRENCH

1991 Semantic feature analysis: Classroom applications, International Reading Association, Newark, 65 pp.

ROSENBLATT, L. M.

1976 Literature as exploration, Modern Language Assoc., New York.

QUINTANA, Hilda E.

2004 "La enseñanza de la comprensión lectora», documento en línea: http://www.huascaran.edu.pe/docentes/archivo/2004/articulos/16-02-04ense_comlectora.doc 


\section{SILVANA SALAZAR AYLLÓN}

SALAZAR, Silvana

2000 Hacia la construcción de un nuevo paradigma en la bibliotecología: la lectura, Informe profesional, EAP de Bibliotecología y Ciencias de la Información, UNMSM, Lima.

SALAZAR, Silvana y Dante PONCE

1999 Hábitos de lectura, INLEC, Lima, 142 pp.

SOLÉ, Isabel

2000 Estrategias de lectura, ICE de la Universidad de Barcelona, GRAO, Barcelona, $176 \mathrm{pp}$.

WARNING, Rainer (ed.)

1989 Estética de la recepción, Visor, Madrid, 313 pp. 